\title{
Cardiac Involvement in Ankylosing Spondylitis
}

\author{
Yasemin Ozkan
}

\begin{abstract}
Ankylosing spondylitis is one of the subgroup of diseases called "seronegative spondyloarthropathy". Frequently, it affects the vertebral colon and sacroiliac joint primarily and affects the peripheral joints less often. This chronic, inflammatory and rheumatic disease can also affect the extraarticular regions of the body. The extraarticular affections can be ophthalmologic, cardiac, pulmonary or neurologic. The cardiac affection can be $2-10 \%$ in all patients. Cardiac complications such as left ventricular dysfunction, aortitis, aortic regurgitation, pericarditis and cardiomegaly are reviewed.
\end{abstract}

Keywords: Ankylosing; Spondylitis; Aortic diseases

\section{Introduction}

Ankylosing spondylitis (AS) is a chronic, inflammatory and rheumatic disease from the group of spondyloarthropathies (SPAs), which primarily involves the sacroiliac joint and spine, and less frequently peripheral joints, and can also present with non-joint involvement. The disease frequently affects young adult males. The human leukocyte antigen (HLA)-B27, present in the majority of the patients, contributes to pathophysiological mechanisms of the disease [1]. Non-joint involvement may be observed as ophthalmological, pulmonary, neurological, and cardiac manifestations. Cardiac involvement in AS patients has been reported at the rate of 2-10\% [1-3]. Cardiac involvement in AS may be in the form of aortic insufficiency, aortitis at the ascending aorta, atrioventricular (AV) block, or branch block. The most frequently observed complications are conduction defects and aortic insufficiency. Mitral insufficiency in AS is rare, but can cause cardiac failure [4-7]. Cardiovascular system involvement is more frequent in patients with long-term AS and with peripheral joint involvement [8].

Manuscript accepted for publication March 30, 2016

Physical Medicine and Rehabilitation, Department of Medicine, University of Dumlupinar, 4300 Kutahya, Turkey. Email: ftrjo@hotmail.com

doi: http://dx.doi.org/10.14740/jocmr2488w
The frequency of aortic dissection has been reported as approximately 2.9 in 100,000 [9]. It is the most fatal disease that involves the aorta [10]. The most frequently observed symptom in these patients is chest pain; however, it may present with atypical findings, such as having no pain or as the presence of cardiac, neurological, or ischemic extremities [11, 12]. Aortic dissection is generally observed between the ages of 50 and 70 years, and is found in men at a rate that is double of that observed in women [11]. Hypertension is the leading etiological agent [11]. In addition, causes such as acute joint rheumatism, syphilis, traumatic aortic insufficiency, bacterial endocarditis, Marfan's syndrome, and AS weaken the tunica media of the aorta in particular, and form the basis for the dissection to develop [13].

Sources of stroke can appear within lesions, especially those within the proximal aorta, and paraplegia can develop in cases with distal lesions that involve the spinal arteries. Even though stroke and paraplegia develop rarely, their incidence in cases of aortic dissection is between $2 \%$ and $8 \%$ [14].

\section{Mechanism of AS, Cardiac and Vascular Pa- thologies}

Inflammatory cellular infiltrates, cytokines, genetic, and environmental factors are suspected to contribute to the etiology of AS. Many studies have demonstrated that chronic, systemic, and inflammatory states within the SPAs may also cause cardiac and vascular pathologies [15]. Some studies have reported that cardiovascular mortality increases in patients with AS [16]. Although cardiac involvement may be clinically asymptomatic in patients with AS, it can cause significant problems in some patients. The incidence of cardiovascular involvement in AS ranges between $10 \%$ and $30 \%$ [16].

When it is taken into account that cardiac changes may start before the clinical symptoms of AS present, early diagnosis and treatment are even more important [17-19]. More than one method is described in the literature, such as 24-h Holter monitoring and echocardiography, to assist in assessing the cardiac signs of rheumatic disease [19]. Yildirir et al have demonstrated that the calculation of QT dispersion on a standard ECG revealed valuable information regarding arrhythmias in a more economic, easily applicable and rapid manner. Patients at an increased risk for arrhythmias could therefore be directed 
for more advanced examinations. The increased frequency of aortitis in patients with AS was first found in the 1930s. Today, it is known that AS is not only related to aortic pathology, but also to cardiac complications such as left ventricular diastolic dysfunction, pericarditis and conduction disorders (AV block or branch block), and rarely mitral insufficiency, cardiac failure and cardiomegaly [1, 20-22].

\section{Conduction and Rhythm Abnormalities}

The most frequently observed cardiac sign in AS patients is a conduction abnormality, which generally precedes other cardiac findings such as valve insufficiency [16]. Cardiac involvement has been detected in $5-10 \%$ of patients with AS in the form of a conduction disorder or aortic insufficiency $[23,24]$. Although rheumatological signs of AS are absent in HLA-B27-positive patients, an increase in conduction disorders in these patients has been detected [23]. Indeed, 20\% of patients with permanent pacemakers have been found to be positive for HLA-B27 [22]. In a study by Dik et al [23], first-degree AV block conduction disorder was shown to have a significantly higher prevalence in AS patients compared to the normal population and conduction disorders were associated with disease activity and duration. There are two common theories about the etiology of conduction disorders in patients with AS: inflammation that leads to damage to the interventricular septum wall and AV node dysfunction that forms as a result of damage to the arterial supply to the AV node [23]. These processes combine to contribute to AV extrasystole and the formation of AV block [19, 23]. Toussirot et al [25] suggested that autonomic nervous system irregularities can lead to conduction defects and arrhythmias, and therefore affect prognosis unfavorably. In patients with AS, they have defined ESR and CRP levels and disease severity as factors associated with the autonomic nervous system [9, 25, 26]. Yildirir et al [26] did not find a statistically significant difference between AS patients and the control group in terms of autonomic dysfunction, but accepted that the study was limited by the fact that all patients were young and on significant anti-inflammatory treatment, which could have slowed or stopped the progression of autonomic dysfunction.

\section{Valve Involvement}

In $\mathrm{AS}$, the presence of aortic root and valve disease is related to the duration of underlying disease [1]. One of the primary pathophysiological explanations for valve disease in AS proposed by Bulkley and Roberts has been that aortic root dilatation results from fibrous growth along the intima [27], after they examined the autopsy findings of eight patients with AS. In more detailed examinations, it has been observed that the cellular inflammatory process that leads to endarteritis around the aortic root and valve and is sustained by platelet aggregation leads to tissue thickening, as well as to aortic valve insufficiency by stimulating fibroblast hyperactivity $[1,28]$. In their study, Roldan et al [28] examined the aortic root and valves us- ing transthoracic echocardiography (TEE) in patients with AS, and found aortic root and valve disease in $82 \%$ of patients with AS compared to the control group. Other findings included aortic root thickening, increased aorta root stiffness and vessel dilatation. In their study with follow-up for $>39$ months, they detected 25 patients (24\%) who developed new aortic root or valve abnormalities, while current valve insufficiencies significantly worsened in $12 \%$, and abnormalities were resolved in $20 \%$. Valve replacement was performed in $20 \%$ of patients who developed cardiac failure.

Aortic valve insufficiency is mostly observed in patients with AS; however, mitral insufficiency does occur but at a lesser frequency [1]. The suggested mechanism is that the fibrosis of sub-aortic tissues may reach the mitral valve leaflets. Therefore, fibrosis directly causes mitral insufficiency and consequently decreased mitral valve mobility. Another potential mechanism that causes mitral insufficiency is mitral valve stenosis, caused by left ventricular hypertrophy as a result of severe aortic insufficiency [1].

\section{Systolic and Diastolic Dysfunction}

It has not been fully clarified whether cardiac changes as a result of AS develop secondary to the primary involvement of cardiomyocytes or secondary to aortic and valvular involvement. In some trials in which the left ventricular function (LVF) of patients with AS was examined, defects in systolic and diastolic functions were frequently reported [24, 29, 30]. Brewerton et al [31] studied myocardial tissue biopsies in 28 patients with AS who had no ischemic heart disease, valve disease or hypertension, and observed a slight increase in diffuse interstitial connective tissue; however, no inflammatory change or amyloid was detected. Furthermore, no hypertrophy was observed in the hearts examined. Of the studies in which systolic functions were examined, Riberio et al [32] detected varying degrees of systolic dysfunction in five patients with apparent contraction disorder in a series of 28 patients, while Brewerton et al [31] have detected this in 16 out of 30 patients. Gould et al [20] described several abnormalities in the myocardial functions of patients with AS. The most important of these is diastolic dysfunction, suggesting a decrease in left ventricular compliance. In their studies, Crowley et al [24] detected diastolic dysfunction at the rate of $20 \%$ (59 patients), and Brewerton et al [31] have detected diastolic dysfunction at the rate of $50 \%$ among 30 patients. The authors suggested from their histopathological data that there was an increase in myocardial inflammation and the connective tissue/myocyte rate. In their studies, Yildirir et al [17] specifically examined the diastolic filling functions of AS patients, showing a statistically significant slow early diastolic filling rate (E-wave rate), and a late rapid diastolic filling rate (A-wave rate). In these patients, early diastolic filling/late diastolic filling rate ratios were assessed as being generally lower than controls. Similarly, Gould et al [20] assessed diastolic dysfunction during activity using radionuclide angiography. The diastolic dysfunction in AS is usually not sufficiently severe to cause diastolic heart failure [21]. 
Coronary flow reserve (CFR) is used to assess the function of coronary arteries in terms of microvascular circulation. Some experts have emphasized the prognostic significance of this measurement in patients with atherosclerosis [18]. In their study published in 2008, Caliskan et al [18] used transthoracic Doppler echocardiography (TTDE) to assess CFR in AS patients, and determined that CFR levels were decreased. Furthermore, CRP and TNF-alpha levels correlated with CFR values in these patients. In another study performed in 2010 with a very limited sample size (17 patients), the myocardial infarct rate was examined in AS patients, and an increase of 2 - 3 fold was found in the infarct rate of the AS population [34]. It is important that there is no difference between the use and type of anti-rheumatic treatment among AS patients with or without a history of myocardial infarct. Divecha et al [35] showed in 2005 that not only the level of inflammatory markers (e.g., CRP and IL-6) increased in patients with AS, but these caused insulin resistance and dyslipidemia as a result of their effects on lipid metabolism and insulin activity, resulting in atherogenesis. It has been reported that a chronic elevation at the levels of these markers, even though sub-clinical, would accelerate the risk for coronary heart disease in patients with no autoimmune diseases $[33,35]$.

\section{Conclusion}

The effects of AS on the cardiovascular system significantly affect mortality and morbidity. If chest pain develops in at-risk individuals, aortic dissection should be considered, and urgent interventions should be performed as appropriate. Therefore, the cardiological examination of patients with AS should be emphasized especially in individuals with long-term disease and who are HLA-B27-positive. The fact that cardiac involvement may occur before the emergence of clinical findings of $\mathrm{AS}$, and that an underlying disease such as AS may be present in patients who have had aortic dissection, should be considered in affected patients.

\section{Conflict of Interest}

No conflict of interest was declared by the authors.

\section{Financial Disclosure}

The author declared that this study has received no financial support.

\section{References}

1. Moyssakis I, Gialafos E, Vassiliou VA, Boki K, Votteas V, Sfikakis PP, Tzelepis GE. Myocardial performance and aortic elasticity are impaired in patients with ankylosing spondylitis. Scand J Rheumatol. 2009;38(3):216-221.

2. O'Neill TW, Bresnihan B. The heart in ankylosing spon- dylitis. Ann Rheum Dis. 1992;51(6):705-706.

3. Graham DC, Smythe HA. The carditis and aortitis of ankylosing spondylitis. Bull Rheum Dis. 1958;9(3):171174.

4. Khan MA. Ankylosing spondylitis. Clinical features. In: Klippel JH, Dieppe PA. Rheumatology. St. Louis: Mosby. 1994;25:1-10.

5. Calin A. Ankylosing spondylitis. In: Maddison PJ, Isenberg PA, Woo P, Glass DN. Oxford Textbook of Rheumatology. Oxford: Oxford University Press, 1998;10581070.

6. Inman RD. Ankylosing spondylitis. In: Klippel JH. Primer on the Rheumatic Disease. Atlanta: Arthritis Foundation. 1997; 189-195.

7. Kilinc S, Dincer F, Kes S, Kabukcu M. Ankilozanspondilittekalptutulumununekokardiyografiledegerlendirilmesi. Romatol Tib Rehab. 1997;8:15-19.

8. Ryall NH, Hellivvell PS. A critical review of ankylosing spondylitis. Critical Reviews in Physical Medicine and Rehabilitation. 1998;10:265-301.

9. Meszaros I, Morocz J, Szlavi J, Schmidt J, Tornoci L, Nagy L, Szep L. Epidemiology and clinicopathology of aortic dissection. Chest. 2000;117(5):1271-1278.

10. Sorensen HR, Olsen H. Ruptured and Dissecting Aneurysms of the Aorta. Incidence and Prospects of Surgery. Acta Chir Scand. 1964;128:644-650.

11. Hagan PG, Nienaber CA, Isselbacher EM, Bruckman D, Karavite DJ, Russman PL, Evangelista A, et al. The International Registry of Acute Aortic Dissection (IRAD): new insights into an old disease. JAMA. 2000;283(7):897903.

12. Farina GA, Kwiatkowski T. Aortic dissection. Prim Care Update Ob/Gyns. 2003;10:161-166.

13. Maier GW, Wechsler AS. Pathophysiology of aortic valve disease. In: Edmunds LH, ed. Cardiac Surgery in the Adult. New York: McGraw-Hill, 1997:835-939.

14. Zull DN, Cydulka R. Acute paraplegia: a presenting manifestation of aortic dissection. Am J Med. 1988;84(4):765770 .

15. Heeneman S, Daemen MJ. Cardiovascular risks in spondyloarthritides. Curr Opin Rheumatol. 2007;19(4):358362.

16. Kazmierczak J, Peregud-Pogorzelska M, Biernawska J, Przepiera-Bedzak H, Goracy J, Brzosko I, Plonska E, et al. Cardiac arrhythmias and conduction disturbances in patients with ankylosing spondylitis. Angiology. 2007;58(6):751-756.

17. Yildirir A, Aksoyek S, Calguneri M, Oto A, Kes S. Echocardiographic evidence of cardiac involvement in ankylosing spondylitis. Clin Rheumatol. 2002;21(2):129-134.

18. Caliskan M, Erdogan D, Gullu H, Yilmaz S, Gursoy Y, Yildirir A, Yucel E, et al. Impaired coronary microvascular and left ventricular diastolic functions in patients with ankylosing spondylitis. Atherosclerosis. 2008;196(1):306312.

19. Yildirir A, Aksoyek S, Calguneri M, Aytemir K, Kabakci G, Ovunc K, Nazli N, et al. QT dispersion as a predictor of arrhythmic events in patients with ankylosing spondylitis. Rheumatology (Oxford). 2000;39(8):875-879. 
20. Gould BA, Turner J, Keeling DH, Hickling P, Marshall AJ. Myocardial dysfunction in ankylosing spondylitis. Ann Rheum Dis. 1992;51(2):227-232.

21. Lautermann D, Braun J. Ankylosing spondylitis - cardiac manifestations. Clin Exp Rheumatol. 2002;20(6 Suppl 28):S11-15.

22. Bergfeldt L, Allebeck P, Edhag O. Mortality in pacemaker-treated patients. A follow-up study of the impact of HLA B27 and associated rheumatic disorders. Acta Med Scand. 1987;222(4):293-299.

23. Dik VK, Peters MJL, Dijkmans PA, Van Der Weijden MAC, De Vries MK, Dijkmans BA, et al. The relationship between disease-related characteristicsand conduction disturbances in ankylosing spondylitis. Scand JRheumotol. 2010;39:38-41.

24. Crowley JJ, Donnelly SM, Tobin M, FitzGerald O, Bresnihan B, Maurer BJ, Quigley PJ. Doppler echocardiographic evidence of left ventricular diastolic dysfunction in ankylosing spondylitis. Am J Cardiol. 1993;71(15):1337-1340.

25. Toussirot E, Bahjaoui-Bouhaddi M, Poncet JC, Cappelle S, Henriet MT, Wendling D, Regnard J. Abnormal autonomic cardiovascular control in ankylosing spondylitis. Ann Rheum Dis. 1999;58(8):481-487.

26. Yildirir A, Aksoyek S, Calguneri M, Aytemir K, Apras S, Kiraz S, Kabakci G, et al. No evidence of cardiac autonomic involvement in ankylosing spondylitis, as assessed by heart rate variability. Clin Rheumatol. 2001;20(3):185188.

27. Bulkley BH, Roberts WC. Ankylosing spondylitis and aortic regurgitation. Description of the characteristic cardiovascular lesion from study of eight necropsy patients.
Circulation. 1973;48(5):1014-1027.

28. Roldan CA, Chavez J, Wiest PW, Qualls CR, Crawford $\mathrm{MH}$. Aortic root disease and valve disease associated with ankylosing spondylitis. J Am Coll Cardiol. 1998;32(5):1397-1404.

29. Alves MG, Espirito-Santo J, Queiroz MV, Madeira H, Macieira-Coelho E. Cardiac alterations in ankylosing spondylitis. Angiology. 1988;39(7 Pt 1):567-571.

30. O'Neill TW, King G, Graham IM, Molony J, Bresnihan B. Echocardiographic abnormalities in ankylosing spondylitis. Ann Rheum Dis. 1992;51(5):652-654.

31. Brewerton DA, Gibson DG, Goddard DH, Jones TJ, Moore RB, Pease CT, Revell PA, et al. The myocardium in ankylosing spondylitis. A clinical, echocardiographic, and histopathological study. Lancet. 1987;1(8540):995998.

32. Ribeiro P, Morley KD, Shapiro LM, Garnett RA, Hughes GR, Goodwin JF. Left ventricular function in patients with ankylosing spondylitis and Reiter's disease. Eur Heart J. 1984;5(5):419-422.

33. Radford EP, Doll R, Smith PG. Mortality among patients with ankylosing spondylitis not given X-ray therapy. N Engl J Med. 1977;297(11):572-576.

34. Peters MJ, Visman I, Nielen MM, Van Dillen N, Verheij RA, van der Horst-Bruinsma IE, Dijkmans BA, et al. Ankylosing spondylitis: a risk factor for myocardial infarction? Ann Rheum Dis. 2010;69(3):579-581.

35. Divecha H, Sattar N, Rumley A, Cherry L, Lowe GD, Sturrock R. Cardiovascular risk parameters in men with ankylosing spondylitis in comparison with non-inflammatory control subjects: relevance of systemic inflammation. Clin Sci (Lond). 2005;109(2):171-176. 